\title{
Study and Characterization of a Silver-Selective Membrane Electrode Based on 5-(4-Dimethylaminobenzylidene)rhodanine
}

\author{
M. de los A. Arada Pérez, ${ }^{\mathrm{a},{ }^{*}}$ L. León Duharte ${ }^{a}$ and M. Yazdani-Pedram ${ }^{b}$ \\ ${ }^{a}$ Department of Analytical Chemistry, Eastern University of Cuba, Santiago de Cuba \\ ${ }^{b}$ Polymer Laboratory, Faculty of Chemical and Pharmaceutical Sciences, University of Chile, \\ Sergio Livingstone Pohlhammer 1007, Independencia, Santiago, Chile
}

Received June 20, 2017; accepted January 26, 2018

\begin{abstract}
This paper has carried out the construction and evaluation of a selective electrode for silver, using 5-(4-dimethylaminobenzylidene)rhodanine as ionophore, and diocthyl phthalate (DOP) with plasticizer in PVC. The electrode shows fast potentiometric responses in the concentration range from $10^{-6}$ to $10^{-2} \mathrm{~mol} / \mathrm{dm}^{3}$, with Nernstian slope $(58.2 \pm 0.8 \mathrm{mV} / \mathrm{decade})$, and a response time of $20 \mathrm{~s}$. Also, we presented a theoretical study of the molecule, optimized by DFT to a B3LYP/6-31G (d, p) level of theory. A good agreement was obtained between calculated geometrical parameters using DFT methods and experimental data. Analysis of the ionophore by the natural bond orbital (NBO) allowed explaining the possible centers of coordination with $\mathrm{Ag}^{+}$. Other characteristics of the electrodes were also studied.
\end{abstract}

Keywords: silver-selective membranes, all-solid state ISEs, 5-(4-dimethylaminobenzylidene)rhodanine and chemical sensor.

\section{Introduction}

There were described numerous analytical methods [1-3] for the determination of $\mathrm{Ag}^{+}$in different samples, which included volumetric, spectrophotometric, (ICP), voltamperometric, polarographic and potentiometric methods. These methods are quite laborious, because of the samples treatment. However, by the application of potentiometric methods using selective electrodes for ions (ESI) [4-9], this problem was eliminated.

On one hand, ESI are so useful on different fields such as pollution determinations in potable water, biological samples and electronic industry. In the other hand, silver has many applications in photography, dentistry, among others, and has an inevitable relationship with the development of a relatively large number of silver ion sensors based on different ionophores [10-21].

In this work, the ionophore was theoretically characterized and analyzed by the natural bond orbital (NBO), explaining the possible centers of coordination of

\footnotetext{
* Corresponding author. E-mail address: mayarada@uo.edu.cu
} 
$\mathrm{Ag}^{+}$binding to 5-(4-dimethylaminobenzylidene)rhodanine, through its exocyclic sulphur atom, when the molecule is not protonated. Also, some parameters of ESI for the silver study were characterized using 5-(4-dimethylaminobenzylidene)rhodanine, with diocthyl phthalate as plasticizer, in a polyvinyl chloride membrane.

\section{Experimental}

\section{Materials and methods}

All the reagents used in this study had analytical grade. Poly(vinylchloride) (PVC) from Fluka was used as a polymeric matrix. The used plasticizer was diocthyl phthalate (DOP), from Merck. Tetrahydrofurane (THF) was of analytical grade, from Merck, and 5-(4-dimethylaminobenzylidene)rhodanine was employed as ionophore, from Pancreac. The water used in this work was bidistilled, with a conductivity of less than $2 \mu \mathrm{S} / \mathrm{cm}^{-1}$.

The epoxy conducting resin was prepared by mixing a commercial twocomponent epoxy adhesive, from Ciba-Geigy, with graphite powder, from Merck, as already described by Arada Pérez et al. [22] for nitrate sensors, obtaining a resistance of $\leq 2 \mathrm{k} \Omega$.

A Hanna $\mathrm{pH}$ meter model 213 digital microprocessor, with a precision of \pm 0.1 $\mathrm{mV}$, was used for measuring the potential difference between reference and indicator electrodes. The reference electrode used in this study was an $\mathrm{Ag} / \mathrm{AgCl}$ HI 5311 double junction electrode. A solution of $0.1 \mathrm{~mol} / \mathrm{dm}^{3}$ of $\mathrm{K}_{2} \mathrm{SO}_{4}$ was employed in the external electrode compartment, and a Jenway model 1000 LT hot plate-stirrer was used.

\section{Preparation of the membranes}

The prepared membranes contained Wt. 5\% of 5-(4-dimethylaminobenzylidene)rhodanine as ionophore, Wt. $60 \%$ of diocthyl phthalate as plasticizer, and Wt. $35 \%$ of PVC as the polymeric matrix. The preparations of the electrode were carried out in a similar manner as the method employed for the construction of the all-solid-state ion selective electrodes reported in the literature [22].

\section{Scheme of the design of the ESI for Ag}

The used elements for the construction of the selective electrodes carried in a disposable small syringe were a coaxial cable, a resin support epoxy conductive and a membrane.

\section{Preparation of the body of the electrode}

The electrode body was prepared from a hypodermic syringe of the type used for insulin (Fig. 1a - e), placing a distance of one of its extremes of approximately 5 $\mathrm{mm}$ from a copper plate (Fig. 1c), and cleaning it previously with a solution of $\mathrm{HCl}_{\text {(ac ) }} 1: 1$. The electrode was fixed once the copper ring on the syringe and the composite graphite-epoxy were placed. The sensor membrane was deposited over it (Fig. 1). 


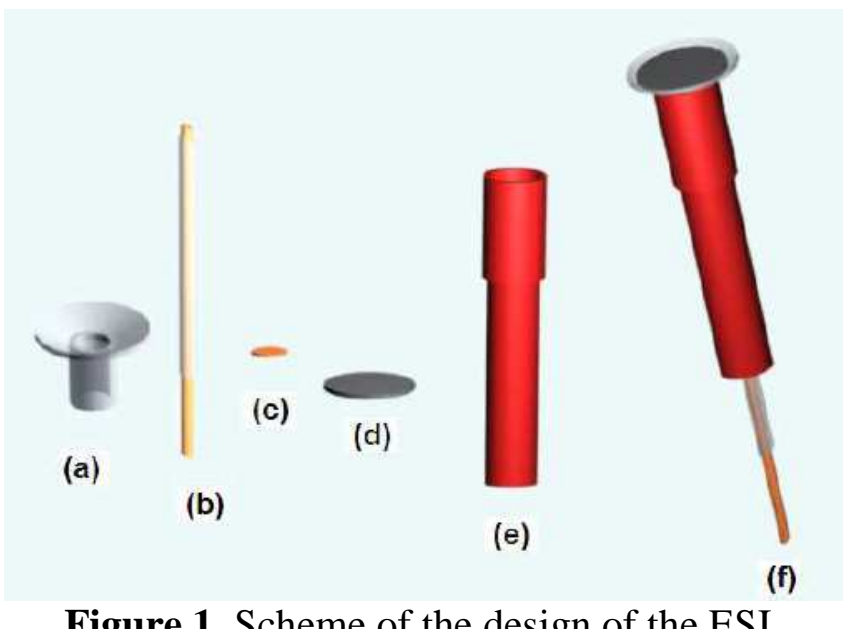

Figure 1. Scheme of the design of the ESI.

\section{Preparation of the support}

A conductive resin was deposited on the copper plate (Fig. 1d) and over it, and the membrane sensor support was located. The epoxy conductive resin was obtained weighing $0.1483 \mathrm{~g}$ of araldite, $0.006 \mathrm{~g}$ of HP hardener and $0.25 \mathrm{~g}$ of powdered graphite. At a later time, the reagents blend in with the help of an agitating rod in a suitable container, so that the resulting material would be the most homogeneous possible. Next, the material was deposited at the cavity of the body of the electrode with the help of the rod, firmly pressing the mixture onto the copperplate, to assure an optimal electric contact. The resin epoxy deposited leaves were dried to $40{ }^{\circ} \mathrm{C}$ during a minimum of 12 hours, to get its total hardening too. Once dried, the surface lost approximately $0.3 \mathrm{~mm}$ of thickness underneath the level of the support tube, to enable the depositing of the liquid membrane.

\section{Determination of the electromotive force (EMF)}

The electromotive force (EMF) determinations were carried out by using an open cell (Fig. 2) at ambient temperature. The composition of the electrochemical cell was:

$\mathrm{Ag} / \mathrm{AgCl}\left|\mathrm{KCl} \quad 0.1 \quad \mathrm{~mol} / \mathrm{dm}^{3}\right| \mathrm{K}_{2} \mathrm{SO}_{4} \quad 0.1 \quad$ mol/dm ${ }^{3} \mid$ test $\quad$ solution||PVCmemb.|cond. supp. $\mid \mathrm{Cu}(s)$

The calibration curves were used to calculate such parameters as slope (S), practical detection limit (PDL) and lower limit of linear response (LLLR). This was done following the Nernst law, through data adjustment by the linear regression method. The calibration parameters were obtained by applying the method of additions [23], determining the activity of the principal ion by using the Debye-Hückel equation.

$$
\log f=0.51 Z^{2} I^{1 / 2} / 1+I^{1 / 2}
$$

The effect of the $\mathrm{pH}$ response on the PVC membrane electrode was tested using $1.0 \times 10^{-2} \mathrm{~mol} / \mathrm{dm}^{3} \mathrm{AgNO}_{3}$ solutions. The $\mathrm{pH}$ was adjusted by using small drops of nitric acid or sodium hydroxide solutions. 
The selectivity coefficients ( $K_{A B}^{P o t}$ ) were determined by using the method of mixed solutions [23], through equation 2 .

$$
K_{A B}^{P o t}=\frac{a_{A}}{a_{B} Z_{A} Z_{B}}
$$

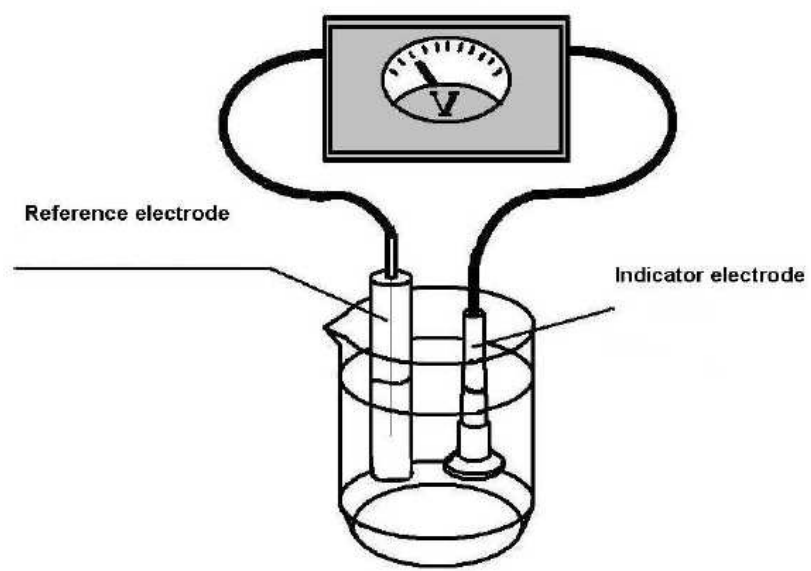

Figure 2. Schematic diagram of the potentiometric cell with an ion-selective electrode (ISE) as the indicator electrode, and the reference electrode used in this study $(\mathrm{Ag} / \mathrm{AgCl}$ double junction).

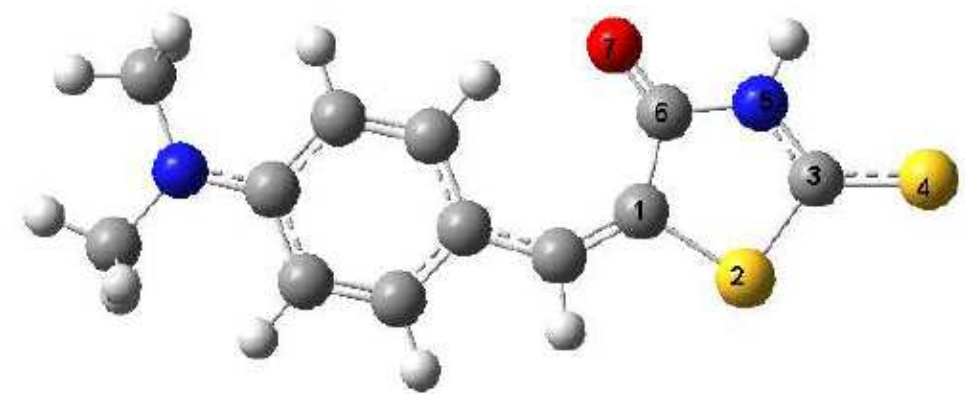

Figure 3. Optimized structure of the 5-(4-dimethylaminobenzylidene)rhodanine.

\section{Results and discussion}

\section{Theoretical study of the ionophore}

The ionophore theoretic study by DFT (Density Functional Theory) was carried out to a level of theory B3LYP/6-31G (d, p). In Fig. 3, it is showed a representation of the optimized geometry of 5-(4-dimethylaminobenzylidene)rhodanine, numbering the atoms of the thioamide ring, which is the region of interest to form a complex with silver, due to the presence of heteroatoms of soft character, such as nitrogen and sulfur.

As it can be observed, the rings are almost coplanar, so you should expect a high probability of conjugation between them. In the figure, it is showed that the ketothionic tautomer is stable, a feature which is consistent with the infrared spectrum of the molecule.

To analyze the electronic delocalization, it was used the electronic occupation which presents the atoms of interest. The N5 has occupancy of 1.60, which is 
lower than any of the values found in sulphur (1.98 and 1.86). In Fig. 4 we can observe the HOMO of the ionophore molecule which shows the highest density of negative charge on the benzene ring, due to the combination that exists in the latter.

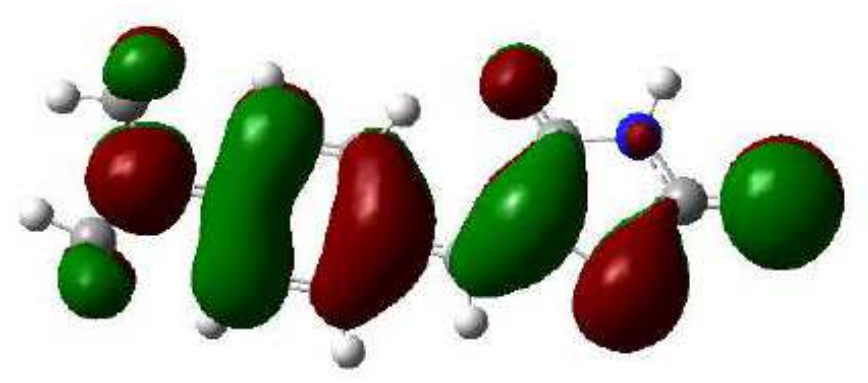

Figure 4. Graphical representation of HOMO orbital of the optimized molecule.

On the exocyclic sulphur atom, it is also possible to observe some negative charge density, because of its couplets and unshared electron pairs, but not on the imino nitrogen. Taking into account the value of occupation, the Mulliken charges and this figure, we could think of the delocalized electronic pair of N5 with adjacent groups.

The analysis of second-order interactions made with the Natural Bond Orbital (NBO) is an efficient method for the study of intra and intermolecular bonds between donor and acceptor species of electrons, in addition to the interactions between bonds. In Table 1 it can be observed second-order interactions among the most significant existing Lone Pairs (LP) of S4 and N5, with adjacent links of ring.

Table 1. Second order interactions.

\begin{tabular}{|c|c|}
\hline Nature of the interaction & E(2) $\left(\right.$ kcal.mol $\left.^{-1}\right)$ \\
\hline$L P P 5 \rightarrow C 3-S 4$ & 71.02 \\
\hline $\mathrm{LP} \quad \mathrm{N} 5 \rightarrow \mathrm{C6}-07$ & 51.68 \\
\hline $\mathrm{LP} 1 \mathrm{S4} \rightarrow \mathrm{C3}$ & 5.10 \\
\hline$L P 1 S 4 \rightarrow S 2-C 3$ & 4.32 \\
\hline$L P 1 S 4 \rightarrow C 3-N 5$ & 3.88 \\
\hline $\mathrm{LP} 2 \mathrm{S4} \rightarrow \mathrm{S} 2-\mathrm{C} 3$ & 14.04 \\
\hline $\mathrm{LP} 2 \mathrm{~S} 4 \rightarrow \mathrm{C3}-\mathrm{N5}$ & 11.03 \\
\hline
\end{tabular}

As it can be seen, the N5 LP has the greatest interaction, because the electron pair is delocalized in the ring, due to the strength of interactions with carbonyl and thiocarbonyl groups, making it less labile, to form a coordinate bond with the silver ion. However, the S4 LPs have second-order interactions of much less energy. Although there is also a dislocation of their electron pairs (1.86), there is a pair of electrons with an occupancy of 1.98 that is close to 2 . This may indicate an increased availability of $\mathrm{S} 4$ to the formation of the complex, preferably the heteroatom with respect to the imino nitrogen.

In Fig. 5 we can see the representation of the HOMO-1 of the molecule, which corresponds to one electron pair of sulphur. Also, it is possible to see that 
between the imino nitrogen and exocyclic sulfur, the latter is more available to coordinate with $\mathrm{Ag}^{+}$, because $\mathrm{N} 5$ has a greater delocalization of the electron pair, and it is bound to a hydrogen atom.

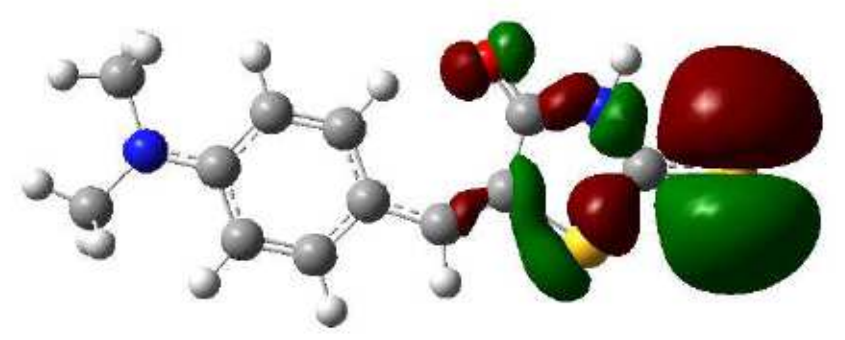

Figure 5. Graphical representation of HOMO-1 orbital of the optimized molecule.

The electrostatic potential generated by the molecule has, for each point in space, the interaction energy between the molecule, and a positive point charge, which is located at that point. This parameter is probably one of the most useful for predicting the reactivity of a molecule. Fig. 6 shows a map of the potential energy surface charge density of the optimized molecule, which displays the regions of space to which they would be attracted to positively charged particles (regions of negative electrostatic potential, red color), or negatively charged particles (positive electrostatic potential regions, blue color).

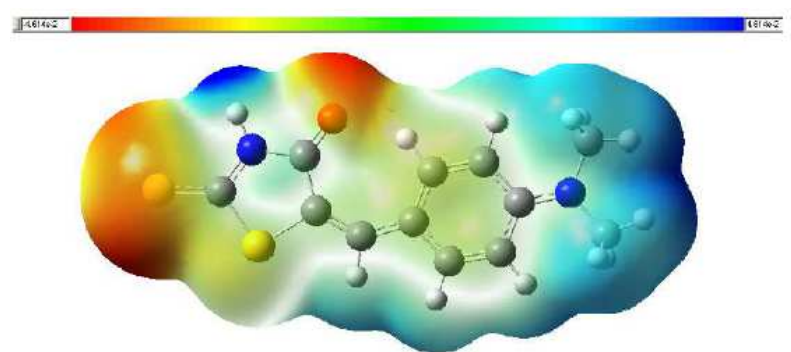

Figure 6. Representation of the ionophore showing the potential energy surface.

Fig. 5 shows that the regions of higher density of present negative charges are S4 and 07 . These regions are likely to form a coordinate bond with a metal ion. The carbonyl group of the center ring is harder than sulphur, to coordinate with a soft metal such as silver $(16,99.100)$. To better understand this part, Fig. 7 shows the orbital Homo mapped with potential energy surface (EPS).

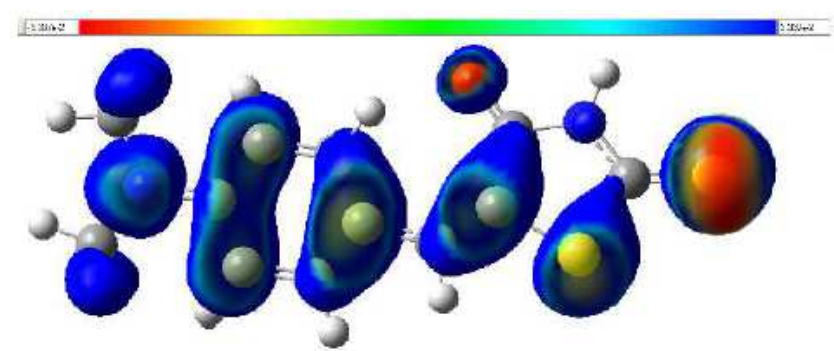

Figure 7. Graphical representation of HOMO orbital mapping with EPS. 
We can observe that the region of highest negative charge density is S4. This area is available for the formation of a bond with a metal ion, a feature that is consistent with what was previously discussed.

According to Pearson theory of hard and soft acids and bases, the $\mathrm{Ag}^{+}$ion is a soft acid. Therefore, preferably, the coordination for the formation of complexes with ligands that have a mixture of donor atoms (as is the case in question) is possible for nitrogen, due to the greater negative charge density, and because both nitrogen and sulfur are simultaneously provided when available. So, it can be said that the $\mathrm{Ag}^{+}$ion will coordinate with the exocyclic sulphur atom of 5-(4dimethylaminobenzylidene)rhodanine, when the molecule is not deprotonated. However, when you release the hydrogen atom bonded to the nitrogen atom, this may be possible by either coordination, or simultaneously both.

\section{Parameter of sensor}

The potential response of the sensors at varying concentrations of the silver ion (Fig. 8, calibration graph) shows a wide concentration linear range, in the order of $10^{-6}$ to $10^{-1} \mathrm{~mol} / \mathrm{dm}^{3}$, with a slope of $58.2 \pm 0.8 \mathrm{mV} /$ decade of activity.

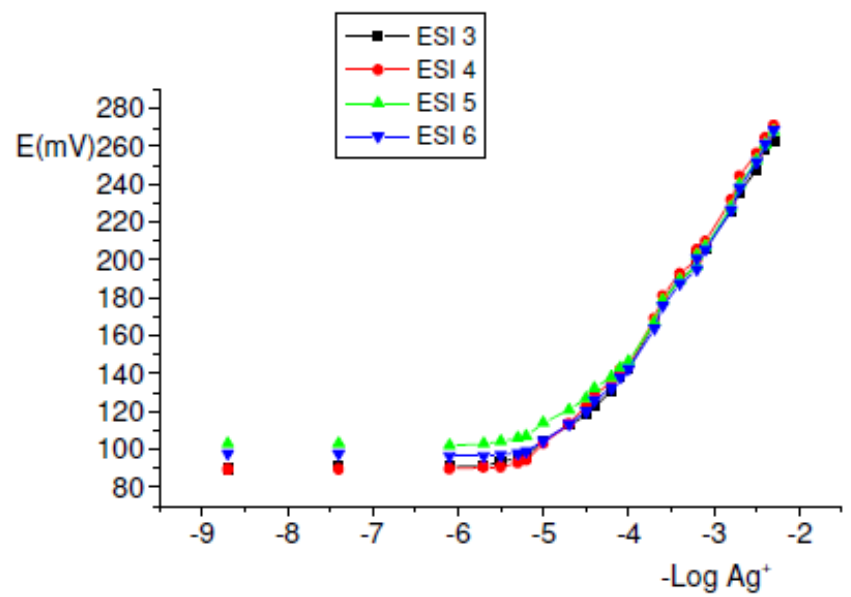

Figure 8. Calibration curves obtained by the additions method for the sensors prepared, by using DOP, with plasticizer.

As it can be seen from Table 2, the values for the slope $(\mathrm{S})$ correspond to those expected by Nernst for a monovalent ion.

The detection limit was determined from the intersection of the two extrapolated segments of the calibration plots.

The $\mathrm{pH}$ response profile for the sensor was tested using $1.0 \times 10^{-2} \mathrm{~mol} / \mathrm{dm}^{3}$ $\mathrm{AgNO}_{3}$ solutions. The potential remains constant in ranges from 2.0 to 4 and 4.5 to 6.0 (Fig. 9). 
Table 2. Calibration parameters of the electrode obtained employing the addition method, with DOP plasticizers used as solvent mediators in this study.

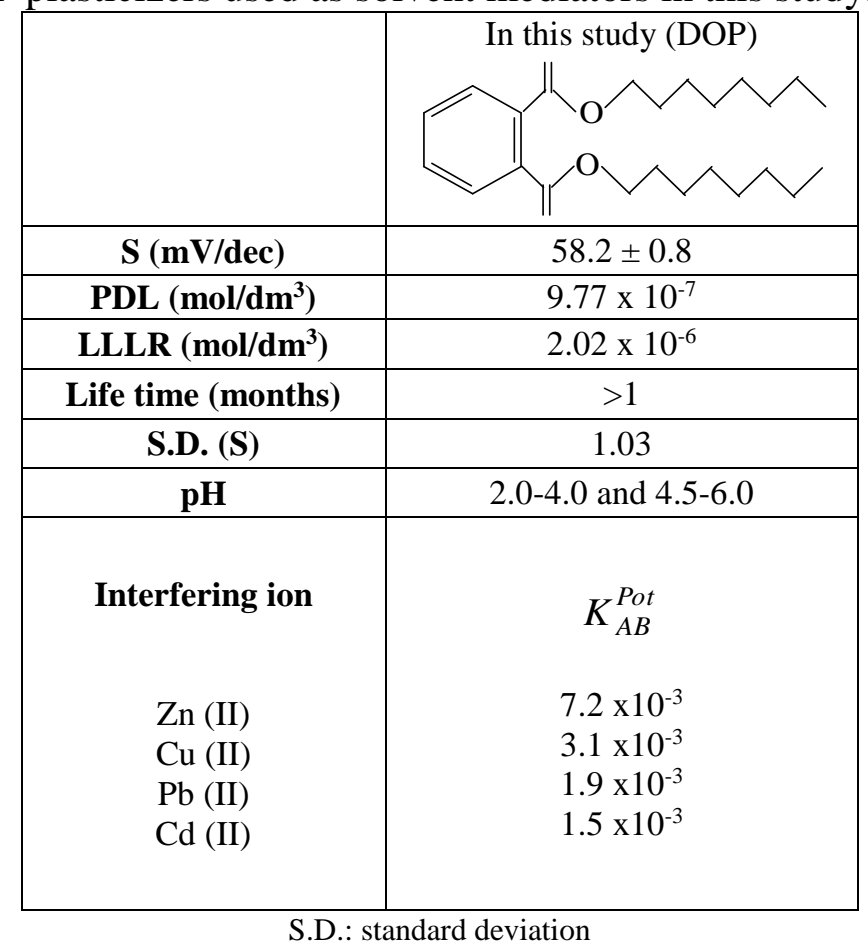

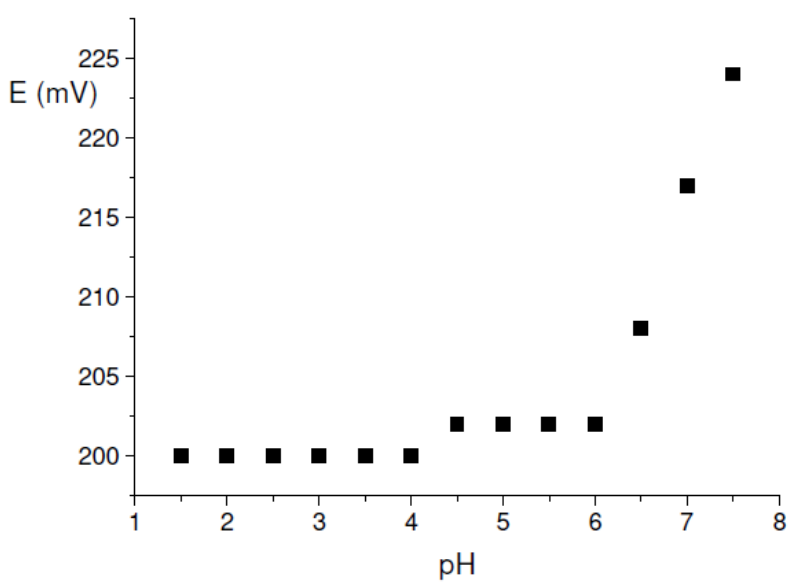

Figure 9. Study of the $\mathrm{pH}$ influence on the potential of the electrode response.

There can be observed three definite regions in the graphic:

Region 1: PH $(2.0-4.0)$ - the potential is held constant in this range, showing a Nernstian slope;

Region 2: $\mathrm{pH}(4.5-6.0)$ - between the first region and this one, there is a slight increase in the potential, after which it keeps constant;

Region 3 pH: $(6.0-11.0)$ - to $\mathrm{pH}$ values higher than the inferior limit of this region potential there is an increase in $\mathrm{Ag}^{+}$because of the hydrolysis of the ion and of silver hydroxide formation in the solution. As from $\mathrm{pH}$ 8, one observes $\mathrm{Ag}_{2} \mathrm{O}$ formation, with a precipitated brown-colour. What happens at the regions 1 and 2 may be the following: as the formation of a complex between a metallic ion is known and it is binding, one can depend on the $\mathrm{pH}$ values; also, it is demonstrated in the bibliographic revision that, in the 
formation of complexes with $\mathrm{Ag}^{+}$in the presence of ligands with a mixture of atoms donors, such as nitrogen and sulphur, the coordination for both is simultaneously possible (nitrogen and sulphur), if and when they are available. There is a fast stability in the response of the showed electrode $(20 \mathrm{~s})$.

The effect of the interfering ion on the response behaviour of the sensors determinated a $1.0 \times 10^{-2} \mathrm{~mol} / \mathrm{dm}^{3}$ concentration. It employed the mixed solution method [24] based on the Nicolsky-Eisenman equation (for the coefficients of selectivity potentiometric), and worked with three responses and three determinations in the studied time.

\section{Conclusions}

The new electrode described in the present work has high sensitivity, stability and response time; it showed a linear response in the concentration range from $10^{-6}$ to $10^{-2} \mathrm{~mol} / \mathrm{dm}^{3}$, a slope of $58.2 \mathrm{mV} /$ decade, a PDL of $9.77 \times 10^{-7} \mathrm{~mol} / \mathrm{dm}^{3}$ and a LLLR of $2.02 \times 10^{-6} \mathrm{~mol} / \mathrm{dm}^{3}$. The selectivity coefficients ranged at about $10^{-3}$ by the studied anions ( $\mathrm{Zn}$ (II), $\mathrm{Cu}$ (II), $\mathrm{Pb}$ (II) and $\mathrm{Cd}$ (II)), indicating they would not significantly disturb the functioning of the $\mathrm{Ag}^{+}$selective membrane. The proposed electrode can be used for silver ion determination.

\section{References}

1. Rains T, Watters R, Epstein M. Application of atomic absorption and plasma emission spectrometry for environmental analysis. Environ Int. 1984;10:163168.

2. Ayres G. Análisis Químico Cuantitativo. Editorial Pueblo y Educación. 1978;225:344-345.

3. APHA. Standard Methods for examination of water and wastes. 17th edition. 1989.

4. Casabó J, Pérez-Jiménez C, Escriche L, et al. Silver(I) Ion- Selective Electrodes Based on Dithiamacrocycles. Chem Lett. 1990;7:1107-1108.

5. Amini MK, Rafi A, Mohammadpoor-Baltork I. Silver-selective membrane electrode using 2-mercaptobenzimidazole and 2-mercaptobenzothiazole carries. Electrochemistry. 2002;35:1795-1809.

6. Liu Y, Zhao BT, Chen LX, et al. Liquid Membrane Transport and Silver Selective Electrode Based on Novel Bis (3-Pyridinecarboxylate) Calixarene as Ionophore. Microchem J. 2000;65:75-79.

7. Demirel A, Doan A, Akku G, et al. Silver(I)-selective PVC membrane potentiometric sensor based on a recently synthesized calixarene. Electroanalysis. 2006;18:1019-1027.

8. Yan Z, Lub Y, Li X. Silver ion-selective electrodes based on bis(dialkyldithiocarbamates) as neutral ionophores. Sensor Actuat B-Chem. 2007; 122:174-181.

9. Su CC, Chang MC, Liua LK. New $\mathrm{Ag}^{+}$and $\mathrm{Pb}^{2+}$ Selective Electrodes with Lariat Crown Ethers as Ionophores. Anal Chim Acta. 2001;432:265-271. 
10. Zeng X, Weng L, Chen L, et al. The Synthesis of Some Pyridyl Functionalized Calixarenes as the Sensor Molecule for Silver Ion-Selective Electrodes. J Chem Soc, Perkin Trans. 2001;2:545-549.

11. Mahajan RK, Parkash O. Silver (I) Ion-Selective PVC Membrane Based on Bis-Pyridine Tetramide Macrocycle. Talanta. 2000;52:691-693.

12. Chen L, He X, Zhao B, et al. Calixarene Derivatives as the Neutral Carrier in Silver Ion-Selective Electrode and Liquid Membrane Transport. Anal Chim Acta. 2000;417:51-56.

13. Chen L, Zeng $\mathrm{X}, \mathrm{Ju} \mathrm{H}$, et al. Calixarene Derivatives as the Sensory Molecules for Silver Ion-Selective Electrode. Microchem J. 2000;65:129135.

14. Kimura K, Yajima S, Tatsumi K, et al. Silver Ion-Selective Electrodes Using Coordinate Calixarene Derivatives as Soft Neutral Carriers. Anal Chem. 2000;72:5290-5294.

15. Chen L, Ju H, Zeng X, et al. Silver Ion-Selective Electrodes Based on Novel Containing Benzothiazolyl Calixarene. Anal Chim Acta. 2001;437:191-197.

16. Casabó J, Flor T, Romero MI, et al. Silver-Selective Membrane Electrodes Using Acyclic Dithia Benzene Derivative Neutral Carriers; Comparison with Related Macrocyclic Compounds. Anal Chim Acta. 1994;294:207-213.

17. Liu D, Liua J, Tiana D, et al. Polymeric Membrane Silver-Ion Selective Electrodes Based on Bis (Dialkyldithiophosphates). Anal Chim Acta. 2000;416:139-144.

18. Mashhadizadeh MH, Shamsipur M. Silver (I)-Selective Membrane Electrode Based on Hexathia-18-Crown-6. Anal Chim Acta. 1999;381:111-116.

19. Martínez E. Sensors potenciometric all- solid- state d'amoni i la seva conversió en biosensors d'urea construcció, evaluació aplicació. PhD Thesis. Barcelona:Universidad Autónoma de Barcelona; 1990.

20. Guo SX, Khoo SB. Highly Selective and Sensitive. Determination of Silver (I) at a Poly(8-Mercaptoquinoline) Film Modified Glassy Carbon Electrode. Electroanalysis. 1999;11:891-898.

21. Bao S, Nombra T. Silver-Selective sensor using an electrode separate Piezoelectric Quartz Crystal Modified with a Chitosan Derivation. Anal Sci. 2002;18:881-885.

22. Arada Pérez MA, Marín LP, Quintana JC, et al. Influence of different plasticizers on the response of chemical sensors based on polymeric membranes for nitrate ion determination. Sensor Actuat B-Chem. 2003;89:262-268.

23. IUPAC. Compendium of Analytical Nomenclature. Oxford: Pergamon Press; 1978, p.168-173. 